\title{
In-hospital mortality in older patients after ventricular assist device implantation: A national cohort study
}

Charlotta Lindvall, MD, PhD, ${ }^{\mathrm{a}, \mathrm{b}}$ Brooks Udelsman, MD, MHS, ${ }^{\mathrm{c}}$ Devvrat Malhotra, MD, MPH, ${ }^{\mathrm{d}}$

Ethan Y. Brovman, MD, ${ }^{\mathrm{e}}$ Richard D. Urman, MD, ${ }^{\mathrm{e}}$ David A. D’Alessandro, MD, ${ }^{\mathrm{f}}$ and

James A. Tulsky, MD ${ }^{\mathrm{a}, \mathrm{b}}$

\section{ABSTRACT}

Objectives: To assess baseline patient characteristics and identify factors associated with in-hospital mortality after ventricular assist device (VAD) placement.

Methods: Cross-sectional study using the National Inpatient Sample database from January 2010 to December 2014. Analyses were performed with sample weights provided by the National Inpatient Sample, which are reported \pm the standard error of the mean.

Results: Weighted samples yielded $15,021 \pm 1111$ patients who received a VAD. The mean age at time of implantation was 56.6 years. Most recipients were white $(59.9 \%)$ and male $(75.0 \%)$. Among older patients, in-hospital mortality increased from $17.2 \%$ to $48.2 \%$ when 1 or more high-risk interventions (cardiac surgery, prolonged mechanical ventilation, hemodialysis, or extracorporeal membrane oxygenation) preceded VAD placement $(P<.001)$. In comparison, in-hospital mortality in younger patients increased from $11.1 \%$ to $29.4 \%$ when 1 or more of these same procedures preceded VAD placement. The mortality difference associated with these procedures was $19 \%$ greater in older patients compared with younger patients (95\% confidence interval [CI], 9\%-28\%). In-hospital mortality among VAD recipients was associated with age older than 65 years (odds ratio [OR], 1.76; 95\% CI, 1.29-2.40), female sex (OR, 1.27; 95\% CI, 0.971.67), and at least 1 high-risk intervention preceding VAD (OR, 5.52; 95\% CI, 4.27-7.13).

Conclusions: Older patients who underwent 1 or more intensive treatments before VAD placement had a nearly $50 \%$ inpatient mortality and were unlikely to receive a cardiac transplantation. Refining patient selection might help better align VAD with those most likely to benefit. (J Thorac Cardiovasc Surg 2019;158:466-75)

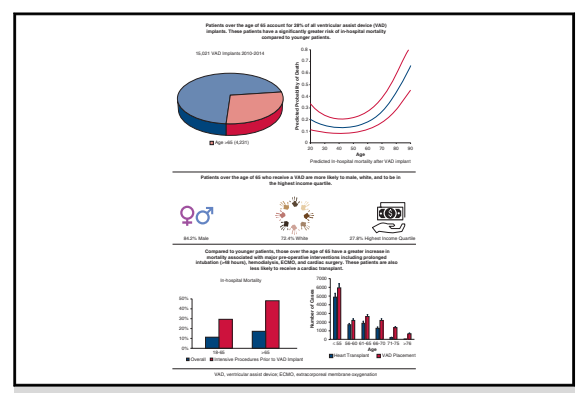

In-hospital mortality in older patients after VAD implantation: a national cohort study.

\section{Central Message}

Older adults who undergo intensive treatments before VAD implantation have a $48.2 \%$ inpatient mortality.

\section{Perspective}

We assessed outcomes after VAD placement in older adults. Older adults who underwent intensive treatments (cardiac surgery, mechanical ventilation, hemodialysis, or ECMO) before VAD implantation had a $48.2 \%$ mortality rate and are unlikely to receive cardiac transplantation. Refining patient selection might help better align treatment with those most likely to benefit.

See Commentaries on pages 476 and 478.
From the ${ }^{\mathrm{a}}$ Department of Psychosocial Oncology and Palliative Care, Dana-Farber Cancer Institute, Boston, Mass; ${ }^{\mathrm{b}}$ Division of Palliative Medicine, Department of Medicine, and ${ }^{\mathrm{e}}$ Department of Anesthesiology, Perioperative and Pain Medicine, Brigham and Women's Hospital, Boston, Mass; ${ }^{\mathrm{c}}$ Department of Surgery, and ${ }^{\mathrm{f}} \mathrm{Di}-$ vision of Cardiac Surgery, Massachusetts General Hospital, Boston, Mass; and ${ }^{\mathrm{d}}$ Harvard School of Public Health, Boston, Mass

Dr. Lindvall was supported by a Junior Faculty Career Development Award from the National Palliative Care Research Center, New York, New York and a 2016 Pilot Award (NINR U24) from the Palliative Care Research Cooperative Group, Denver, Colorado.

Received for publication April 16, 2018; revisions received Sept 10, 2018; accepted for publication Oct 17, 2018; available ahead of print Dec 20, 2018

Address for reprints: Charlotta Lindvall, MD, PhD, Department of Psychosocial Oncology and Palliative Care, Dana-Farber Cancer Institute, 450 Brookline Ave, LW670, Boston, MA 02215-5450 (E-mail: Charlotta_Lindvall@DFCI.harvard. edu).

$0022-5223 / \$ 36.00$

Copyright (C) 2018 by The American Association for Thoracic Surgery

https://doi.org/10.1016/j.jtcvs.2018.10.142
Ventricular assist devices (VADs) have emerged as an alternative to transplantation for the $>250,000$ patients in the United States with end-stage heart failure. ${ }^{1}$ Improved technology has made VAD, and especially left VAD (LVAD), implantation a treatment option for an increasing number of patients, particularly in older adults who are unlikely to receive a heart transplantation. ${ }^{2}$ The proportion of LVADs

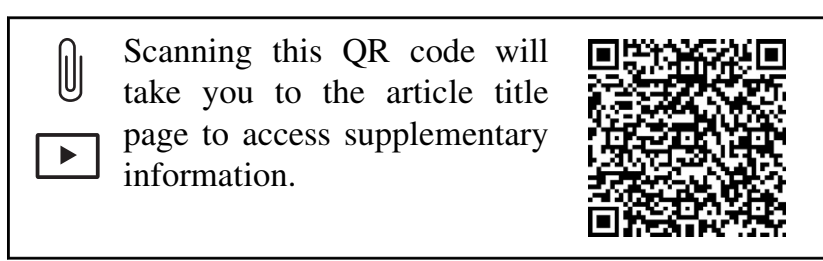




\begin{tabular}{|c|c|}
\hline \multicolumn{2}{|c|}{ Abbreviations and Acronyms } \\
\hline AHRQ & $\begin{array}{l}=\text { Agency for Healthcare Research } \\
\text { and Quality }\end{array}$ \\
\hline $\mathrm{CI}$ & $=$ confidence interval \\
\hline ECMO & $\begin{aligned}= & \text { extracorporeal membrane } \\
& \text { oxygenation }\end{aligned}$ \\
\hline ICD-9 & $\begin{aligned}= & \text { International Classification of } \\
& \text { Diseases, Ninth Revision }\end{aligned}$ \\
\hline ICD-9-PCS & $\begin{aligned}= & \text { International Classification of } \\
& \text { Diseases, Ninth Revision, } \\
& \text { Procedural Coding System }\end{aligned}$ \\
\hline IABP & $=$ intra-aortic balloon pump \\
\hline INTERMAC & $\begin{aligned}= & \text { Interagency Registry for } \\
& \text { Mechanically Assisted Circulatory } \\
& \text { Support }\end{aligned}$ \\
\hline LVAD & $=$ left ventricular assist device \\
\hline NIS & $=$ National Inpatient Sample \\
\hline OR & $=$ odds ratio \\
\hline VAD & $=$ ventricular assist device \\
\hline
\end{tabular}

placed as destination therapy increased from $14.7 \%$ in 2006 to $49.7 \%$ of all LVAD placements in $2014 .^{3}$ At the same time, the number of heart transplantations has remained stable and relatively uncommon in older adults. Currently, only $15 \%$ of heart transplantations are performed in adults older than the age of 65 and less than $2 \%$ in adults older than the age of 70 years. ${ }^{4,5}$

Compared with medical management, VADs improve quality of life, symptoms, and longevity in younger and older patients. ${ }^{6-9}$ However, adverse outcomes such as stroke, gastrointestinal bleeding, early mortality, and rehospitalization are more common among older patients. $^{7,10}$ Furthermore, increased frailty and comorbidities might attenuate the benefit of VAD therapy. VAD therapy requires substantial caregiving, which might be more challenging when the primary caregiver is another older adult. The decision to implant a VAD involves complex trade-offs, and can exert a great effect on patients and families. ${ }^{11,12}$ The expense is also significant, with a mean procedure cost of $\$ 234,808$ in 2011, which is most often paid for by Medicaid and Medicare plans. ${ }^{13}$ An improved understanding of VAD implantation, including hospital outcomes might identify opportunities to optimize patient selection and thereby improve quality by lowering mortality, minimizing unnecessary suffering, increasing access, and reducing cost.

Previous studies have shown increased risk of early mortality after VAD implantation in patients older than the age of 65 years. ${ }^{14}$ In addition, patients who require hemodialysis, intubation, or who undergo same-admission cardiac surgery before VAD placement have an increased risk of early mortality. ${ }^{8,15}$ We hypothesized that in older patients, intensive treatments before VAD placement would result in a greater increase of in-hospital mortality compared with younger patients. We used the National Inpatient Sample (NIS) to compare younger and older patients receiving VADs over a 5-year period (2010-2014). Specifically, we analyzed: (1) demographic and clinical characteristics; (2) differences in hospital course, mortality, and disposition; and (3) temporal trends in the number of VADs placed. We captured and compared the effects of intensive treatments before VAD placement. These treatments included prolonged intubation ( $>96$ hours), hemodialysis, intra-aortic balloon pump (IABP), same-admission cardiac surgery, and extracorporeal membrane oxygenation (ECMO).

\section{METHODS \\ Data Source}

We used the NIS, which is the largest publicly available all-payer inpatient health care database in the United States, yielding national estimates of diagnoses, procedure utilization, and outcomes for hospital inpatient stays from a $20 \%$ stratified sample of US hospitals and is part of the Healthcare Quality and Utilization Project. ${ }^{16}$ The database contains a nationally representative sample from more than 7 million hospitalizations annually. Applying sample weights provided by the NIS, the database projects estimates for more than 36 million hospitalizations annually. The NIS provides data on patient demographic characteristics, in-hospital clinical outcomes, hospital characteristics, and hospital charges. Federal hospitals are not included in the NIS. Quality control and validation of the NIS are performed by the Agency for Healthcare Research and Quality (AHRQ). For all demographic variables, except race/ethnicity, there is $<1 \%$ missing data. Missing race/ethnicity was categorized as "unknown" in our results. Data from the NIS has been used to describe patterns of health care usage and outcomes of major procedures. ${ }^{17,18}$ In addition, data from the NIS has been previously validated in the study of VAD and congestive heart failure. ${ }^{13}$ The database was provided with deidentified patient information and thus deemed exempt from institutional review by the Human Research Committee at Partners HealthCare.

\section{Study Sample and Primary Outcomes}

We included all individuals $\geq 18$ years old who received a VAD during a hospitalization between January 1, 2010 and December 31, 2014. VAD was defined by the International Classification of Diseases, Ninth Revision, Procedural Coding System (ICD-9-PCS) code for VAD placement (37.66). This code is specific to implantation of a durable VAD and excludes temporary procedures such as pulsation balloons and percutaneous external heart assist devices as well as total internal biventricular heart replacement. This code has been stable in its usage throughout the study period. Use of this ICD9-PCS code to identify patients who received a VAD has been previously validated in several studies. ${ }^{13,19}$ We excluded patients who underwent a heart transplantation (ICD-9-PCS code 37.51) or combined heart-lung transplantation (ICD-9-PCS code 37.51) during same admission as VAD placement. The primary outcome of this study was in-hospital mortality. Secondary outcomes included length of hospital stay and hospital charges.

\section{Covariates}

Demographic covariates included age, sex, race/ethnicity, primary insurance type, and median income quartile on the basis of zip code. Race/ ethnicity was reclassified as non-Hispanic white, non-Hispanic black, other (Hispanic, Asian, and Native American), and unknown. Other covariates included type of admission and geographic region (Northeast, Midwest, 
South, and West). Comorbidities were defined using International Classification of Diseases, Ninth Revision, Clinical Modification codes and the Elixhauser comorbidity index. The Elixhauser Index used in this study is a well validated indicator of comorbidities and was designed specifically to measure hospital charges, length of stay, and in-hospital mortality, which were the primary and secondary outcomes of this study. Furthermore, the Elixhauser Index was developed and validated using AHRQ data using the same variables that are reported in the NIS database (also maintained by AHRQ) ${ }^{20}$ In this study, Elixhauser comorbidities were generated from International Classification of Diseases, Ninth Revision, Clinical Modification diagnosis codes using AHRQ Comorbidity Software. ${ }^{21}$

\section{Age Stratification}

Previous reports focusing on in-hospital factors associated with mortality after VAD placement have dichotomized at the age of 65 years. ${ }^{14}$ To determine the validity of dichotomization, we treated age as a continuous variable and used a logistic regression model to plot age against probability of in-hospital mortality after VAD implantation (Figure 1). We determined that mortality risk as a function of age is relatively stable until the age of 65 years, at which point it begins to dramatically increase. Because of the previous categorization of age within the literature and the findings in our regression we chose to categorize age into younger (18-65) and older $(>65)$ categories.

\section{In-Hospital Treatments}

Circulatory support and co-therapy were identified using ICD-9 codes listed in Table E1. All hospital charges were adjusted for inflation with reference to 2014 US dollars, using the latest Consumer Price Index data (http://www.usinflationcalculator.com).

VAD surgery date and admission date were used to determine intensive procedures or treatments that occurred 1 hospital day before VAD placement. A 1 hospital day cutoff was used to ensure invasive treatments directly related to the VAD implantation (eg, mechanical ventilation during surgery) were not included in the analysis. Inpatient intensive procedures or treatments received during admission before VAD implantation were identified using ICD-9 procedure codes. These included IABP, cardiac surgery, mechanical ventilation, hemodialysis, and ECMO. In the case of cardiac surgery, we identified surgeries on the basis of ICD-9 procedure codes, which are listed in Table E1. We included open and endovascular procedures involving the valves and septa, coronary vessels, cardiotomy, pericardiotomy, and ascending aorta.

\section{Statistical Analysis}

All analyses were performed using SAS version 9.4 (SAS Institute Inc, Cary, NC). Frequencies, proportions, and $95 \%$ confidence intervals (CIs) were calculated and weighted to reflect national estimates using inverse sampling weights provided by the NIS. Trend weights were used for 2010-2011 NIS data to adjust for the redesign in 2012. $\chi^{2}$ Tests were used to compare the demographic and clinical characteristics. Continuous variables, such as length of stay and hospital charges, were compared using Wilcoxon rank sum test. Multivariable logistic regression was used to identify associations with in-hospital mortality. We used a model that included all patient demographic characteristics, hospital factors, and comorbidities measured using the Elixhauser comorbidity index. To avoid collinearity we combined preimplantation interventions with significant clinical overlap into a single high-risk intervention variable. Difference-in-difference analysis was used to compare the effects of preoperative interventions on mortality in older and younger patients. Finally, $\chi^{2}$ tests and Wilcoxon rank sum tests were used to compare temporal trends of VAD use, in-hospital mortality, and hospital charges from 2010 to 2014. A 2-tailed $P<.05$ was considered to indicate statistical significance.

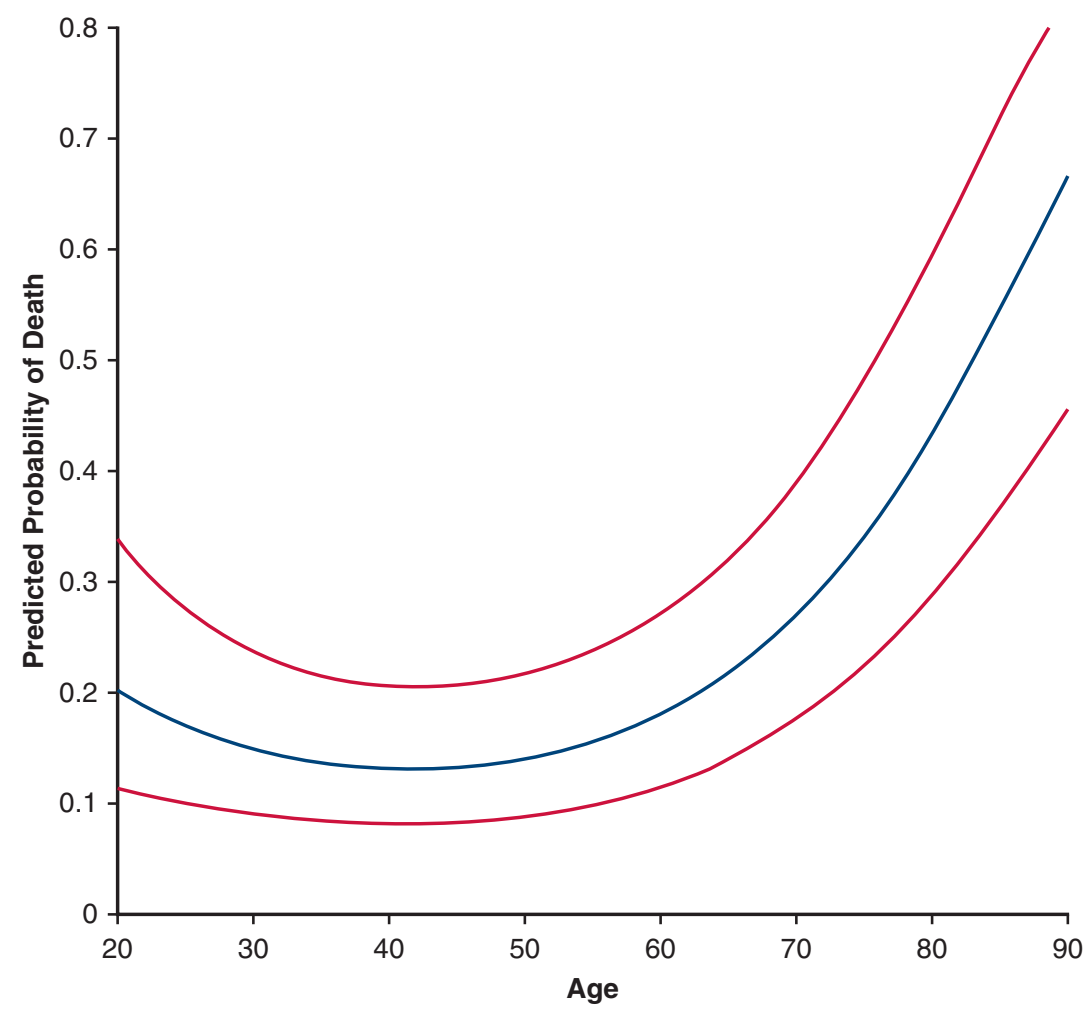

FIGURE 1. Plot of predicted probability of death after ventricular assist device placement in a logistic regression model with age as a continuous variable. Bars around central line represent upper and lower limits of $95 \%$ confidence intervals. 


\section{RESULTS}

\section{Study Population}

Results are expressed as weighted samples \pm the standard error of the mean. We identified 15,021 \pm 1111 episodes of VAD implantation. The demographic characteristics, clinical characteristics, and hospital course of patients receiving a VAD are presented in Table 1. Most of the recipients were white $(59.9 \%)$ and male $(75.0 \%)$. The average score on the Elixhauser Comorbidity Index was $3.60 \pm 0.07$. Individual components of the

TABLE 1. Patient characteristics

\begin{tabular}{|c|c|c|c|c|c|c|c|}
\hline & \multicolumn{2}{|c|}{$\begin{array}{c}\text { Overall } \\
(n=15,021 \pm 1111)\end{array}$} & \multicolumn{2}{|c|}{$\begin{array}{l}\text { Ages 18-65 years } \\
(n=10,790 \pm 782)\end{array}$} & \multicolumn{2}{|c|}{$\begin{array}{l}\text { Ages }>65 \text { years } \\
(n=4231 \pm 329)\end{array}$} & \multirow[b]{2}{*}{$P$ value } \\
\hline & Value & SE & Value & SE & Value & SE & \\
\hline Mean age, y & 56.6 & 0.27 & - & - & - & - & - \\
\hline Male sex, $\mathrm{n}(\%)$ & $11,481(76.4)$ & 827 & 7919 (73.4) & 593 & $3562(84.2)$ & 286 & $<.001$ \\
\hline Elixhauser index, mean & 3.61 & 0.07 & 3.53 & 0.08 & 3.8 & 0.10 & $<.001$ \\
\hline Emergency department admission, $\mathrm{n}(\%)$ & $9778(65.1)$ & 706 & $7155(66.4)$ & 518 & $2623(62.1)$ & 235 & .03 \\
\hline \multicolumn{8}{|l|}{ Race, n (\%) } \\
\hline Non-Hispanic white & 8995 (59.9) & 696 & $5930(55.0)$ & 494 & $3065(72.4)$ & 260 & $<.001$ \\
\hline Black & $3227(21.5)$ & 279 & $2847(26.4)$ & 252 & $380(9.0)$ & 49 & \\
\hline Other* & $1754(11.7)$ & 222 & $1324(12.3)$ & 163 & $430(10.2)$ & 74 & \\
\hline Unknown & $1045(6.9)$ & 168 & $689(6.4)$ & 116 & $356(8.4)$ & 65 & \\
\hline \multicolumn{8}{|l|}{ Primary payer, $\mathrm{n}(\%)$} \\
\hline Medicare & $7282(48.5)$ & 529 & $3684(34.1)$ & 295 & $3598(85.0)$ & 283 & $<.001$ \\
\hline Medicaid & $1666(11.1)$ & 154 & $1636(15.2)$ & 151 & $30(0.7)$ & 12 & \\
\hline Private insurance & $5426(36.1)$ & 415 & $4895(45.4)$ & 377 & $530(12.5)$ & 65 & \\
\hline Other $\dagger$ & $523(3.5)$ & 79 & $461(4.3)$ & 71 & $62(1.5)$ & 19 & \\
\hline \multicolumn{8}{|l|}{ Household income quartile, $\mathrm{n}(\%)$} \\
\hline First (highest income) & $4078(27.1)$ & 343 & $2212(20.9)$ & 232 & $1154(27.8)$ & 140 & $<.001$ \\
\hline Second & $3659(24.4)$ & 289 & $2440(23.0)$ & 204 & $1215(29.3)$ & 112 & \\
\hline Third & $3655(24.3)$ & 285 & $2760(26.0)$ & 237 & $900(21.7)$ & 83 & \\
\hline Fourth (lowest income) & $3366(22.4)$ & 332 & $3196(30.1)$ & 276 & $883(21.3)$ & 100 & \\
\hline \multicolumn{8}{|l|}{ Hospital region, n (\%) } \\
\hline Northeast & $3009(20.0)$ & 467 & $2046(19.0)$ & 328 & $962(22.7)$ & 180 & .01 \\
\hline Midwest & $3812(25.4)$ & 556 & $2740(25.4)$ & 426 & $1072(25.3)$ & 151 & \\
\hline South & $6063(40.4)$ & 670 & $4576(42.4)$ & 512 & $1487(35.1)$ & 186 & \\
\hline West & $2137(14.2)$ & 368 & $1428(13.2)$ & 248 & $709(16.8)$ & 136 & \\
\hline \multicolumn{8}{|l|}{ Discharge disposition, $\mathrm{n}(\%)$} \\
\hline Home & $3902(26.0)$ & 364 & $3185(29.5)$ & 297 & $716(16.9)$ & 95 & $<.001$ \\
\hline Home care & $3573(23.8)$ & 394 & $2112(19.6)$ & 265 & $1462(34.6)$ & 166 & \\
\hline Health care facility & $5608(37.3)$ & 457 & $4284(39.7)$ & 363 & $1323(31.3)$ & 140 & \\
\hline Died & $1933(12.9)$ & 175 & $1204(11.1)$ & 120 & $729(17.2)$ & 81 & \\
\hline \multicolumn{8}{|l|}{ Mean length of stay, $d$} \\
\hline Alive at discharge & 33.2 & 0.68 & 33.3 & 0.72 & 33.2 & 1.01 & .94 \\
\hline Died & 39.0 & 1.89 & 41.9 & 2.44 & 34.3 & 2.42 & .03 \\
\hline \multicolumn{8}{|l|}{ Mean hospital charges, USD } \\
\hline Alive at discharge & 767,431 & 21,023 & 761,354 & 21,367 & 784,155 & 28,579 & .52 \\
\hline Died & $1,037,622$ & 49,259 & $1,065,777$ & 64,374 & 991,547 & 58,889 & .39 \\
\hline \multicolumn{8}{|l|}{ Interventions before $\mathrm{VAD}$ implantation, $\mathrm{n}(\%)$} \\
\hline $\mathrm{IABP}$ & $3278(21.8)$ & 332 & $2343(22.8)$ & 220 & $935(19.5)$ & 112 & .07 \\
\hline Cardiac surgery $\ddagger$ & $557(3.7)$ & 86 & $392(3.6)$ & 52 & $165(3.9)$ & 34 & .62 \\
\hline Mechanical ventilation & $1250(8.3)$ & 151 & $969(9.0)$ & 104 & $281(6.6)$ & 47 & $<.001$ \\
\hline ECMO & $526(3.5)$ & 82 & $431(4.0)$ & 61 & $95(2.2)$ & 21 & $<.001$ \\
\hline Hemodialysis & $575(3.8)$ & 96 & $332(3.2)$ & 52 & $243(5.1)$ & 44 & .01 \\
\hline
\end{tabular}

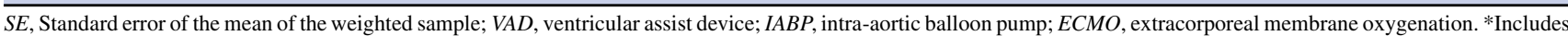
Hispanic, Asian or Pacific Islander, Native American, and other. †Includes self-pay, no charge, and other. łIncludes 5 major groups of surgeries operations on valves and septa, vessels of heart, cardiotomy and pericardiotomy, pericardiotomy and excision of lesion of heart, and major aortic dissection or aneurysm repair. 
Elixhauser Comorbidity Index are listed in Table E2. More than half of the patient population presented through the emergency department $(65.1 \%)$ and a large percentage were covered either through Medicare $(48.5 \%)$ or private insurance $(36.1 \%)$. Overall, mortality was $12.9 \%$; however, nearly half were able to be discharged home without services, or home with additional home care $(49.8 \%)$. The average length of stay was $33.2 \pm 0.68$ days for patients who were alive at discharge and $39.0 \pm 1.89$ days for those who died in-hospital. Similarly, mean hospital charges were $\$ 767,431 \pm \$ 21,0.23$ for patients alive at discharge and $\$ 1,037,622 \pm \$ 49,259$ for those who died in-hospital. Finally, the most common preoperative procedure was IABP, which was performed in approximately 1 in 5 patients. Other major preoperative interventions including prolonged mechanical ventilation, ECMO, hemodialysis, and same-admission cardiac surgery occurred in $<10 \%$ of the study population.

\section{Relation of Age and Mortality}

In stratified analysis, all differences between the age groups were statistically significant (Table 1). Compared with patients ages 18-65 years, older VAD recipients were more likely to be white $(72.4 \%$ vs $55.0 \% ; P<.001)$ and male $(84.2 \%$ vs $73.4 \% ; P<.001)$. Older VAD recipients had a higher Elixhauser index score (3.80 vs 3.53; $P<.001)$. Regional utilization differences also existed, with a higher proportion of older patients receiving a VAD in the West $(16.8 \%$ vs $13.2 \% ; P<.001)$ and Northeast $(22.7 \%$ vs $19.0 \% ; P<.001)$. Patients ages $18-65$ years were more likely to have been admitted through the emergency department $(66.4 \%$ vs $62.1 \% ; P=.03)$. The mean length of stay was $>30$ days in both groups. Patients ages 1865 years who died in-hospital had a longer mean length of stay than patients older than 65 years who died in-hospital (41.9 vs 34.3 days; $P=.03$ ). Total hospital charges were similar in both groups. In both age groups, a significant proportion of patients underwent invasive treatments before VAD placement, which included IABP, cardiac surgery, mechanical ventilation $>96$ hours, ECMO, and hemodialysis. Among these treatments patients between the ages of 18 and 65 years tended to have a high rate of prolonged mechanical ventilation $(9.0 \%$ vs $6.6 \% ; P<.001)$ and use of ECMO $(4.0 \%$ vs $2.2 \% ; P<.001)$. Conversely, those aged $18-65$ years had a significantly lower rate of hemodialysis $(3.2 \%$ vs $5.1 \% ; P=.01)$.

\section{Preoperative Interventions and Mortality}

In-hospital mortality for patients older than 65 years was significantly higher than in patients ages 18-65 years $(17.2 \%$ vs $11.1 \% ; P<.001)$. In-hospital mortality among patients who received intensive procedures/treatments during the index admission before VAD implantation surgery, stratified according to age, is shown in Table 2 and
Figure 2. The 4 procedures/treatments most highly correlated with inpatient mortality were same-admission cardiac surgery, hemodialysis, mechanical ventilation, and ECMO. Among patients older than 65 years, $649 \pm 83(15.3 \%)$ had at least 1 of these procedures, before VAD implantation. Of these patients, $313 \pm 52(48.2 \%)$ died during hospitalization. For patients ages 18-65 years, $1694 \pm 169(15.7 \%)$ had 1 of these 4 procedures before VAD implantation. Of these patients, $498 \pm 65(29.4 \%)$ died during hospitalization. Although having 1 of these procedures increased mortality in younger and older patients, there was a significantly greater increase in mortality in patients older than 65 years.

In our multivariable logistic regression model the 4 highest risk interventions (same-admission cardiac surgery, hemodialysis, mechanical ventilation $>96$ hours, and ECMO) were combined into a high-risk treatment category to avoid collinearity. These high-risk treatments were associated with increased in-hospital mortality (odds ratio [OR], 5.52; 95\% CI, 4.27-7.13). Univariate analysis is reported separately in Table E3. Age older than 65 years was also associated with increased in-hospital mortality (OR, 1.77; 95\% CI, 1.29-2.40; Table 3). However, we did not see a significant interaction effect between age older than 65 years and high-risk treatments in multivariate analysis $(P=.24)$. Elective admission (as opposed to admission through the emergency department) was associated with lower odds of mortality (OR, 0.75; 95\% CI, 0.57-0.98). In multivariate regression, IABP was not associated with a significant change in overall mortality (OR, 0.91; 95\% CI, 0.69-1.20). Because of the categorization of age we performed a sensitivity analysis using age as a continuous variable. There were no changes to the major trends and minimal change in the reported ORs.

\section{Temporal Trends in Heart Transplantation and VAD Placement According to Age}

The number of VAD implantations per year in patients ages 18-65 years increased from $1808 \pm 459$ in 2010 to $2560 \pm 317$ in 2014 (Figure 3). The number of VAD implantations per year in patients older than 65 years more than doubled with $532 \pm 143$ in 2010 to $1100 \pm 120$ in 2014. In-hospital mortality during this period did not significantly change on the basis of age. The rate of heart transplantations declined steadily with age. Of nearly 10,000 heart transplantations, only $1515(15.1 \%)$ were performed in individuals older than the age of 65 years (Figure 4). By the age of 71 years, this number decreased to 229 $(2.2 \%)$, indicating that most of the $2025 \pm 198$ patients with a VAD older than the age of 71 years were unlikely to receive heart transplantation.

\section{DISCUSSION}

The objective of this study was to analyze the baseline demographic characteristics and characteristics of patients 
TABLE 2. Difference-in-difference analysis of mortality according to intervention in patients before receipt of VAD

\begin{tabular}{|c|c|c|c|c|c|}
\hline & \multicolumn{2}{|c|}{ Ages 18-65 years } & \multicolumn{2}{|c|}{ Age older than 65 years } & \multirow[b]{2}{*}{$\begin{array}{c}\text { Mortality difference } \\
(95 \% \text { CI })\end{array}$} \\
\hline & $\begin{array}{c}\text { Died }(\% \text { receiving } \\
\text { treatment })\end{array}$ & $\mathbf{S E}$ & $\begin{array}{c}\text { Died (\% receiving } \\
\text { treatment) }\end{array}$ & SE & \\
\hline IABP & $350(15.0)$ & 48 & $150(16.2)$ & 31 & $1.0 \%(-5.0-7.0)$ \\
\hline Cardiac surgery* & $76(19.5)$ & 19 & $68(41.1)$ & 20 & $22 \%(5.0-39)$ \\
\hline Mechanical ventilation & $263(27.1)$ & 40 & $113(40.1)$ & 24 & $13 \%(1.0-26)$ \\
\hline ECMO & $183(42.4)$ & 34 & $50(52.4)$ & 16 & $10 \%(-15-34)$ \\
\hline Hemodialysis & $159(47.8)$ & 33 & $173(71.1)$ & 34 & $23 \%(4.0-42)$ \\
\hline At least 1 intervention excluding $\mathrm{IABP}^{\dagger} \dagger$ & $498(29.4)$ & 65 & $313(48.2)$ & 52 & $19 \%(9.0-28)$ \\
\hline Baseline in-hospital mortality after VAD implantation & $1204(11.1)$ & 120 & 729 (17.2) & 81 & $6.1 \%(+5.3-7.1)$ \\
\hline
\end{tabular}

receiving VADs and determine the effect of preimplantation interventions on in-hospital mortality. We found that inhospital mortality after VAD placement begins to rapidly increase in patients older than the age of 65 years. Although previous studies have reported increasing age to be a risk factor for early mortality, ${ }^{8,14,19}$ our study shows an explanation for this finding. Intensive procedures before VAD placement resulted in a nearly $50 \%$ in-patient mortality in older patients. Finally, this work confirmed a low rate of cardiac transplantations in patients older than the age of 65 years, indicating that most VAD placements in this older age group was destination therapy rather than a bridge to transplantation (Graphical Abstract). The high rate of inpatient mortality in older adults who have intensive procedures before VAD placement, coupled with the unlikelihood of cardiac transplantation, is an important distinction and deserves recognition by clinicians and discussion with patients (Video 1).

The dichotomization of age in epidemiologic studies has the potential to bias analysis and requires ample clinical justification. ${ }^{22}$ Although age has been dichotomized in previous studies focusing on VAD placement, ${ }^{10,14}$ we chose to further validate this decision. Using linear regression, we showed an exponential increase of in-hospital mortality after VAD placement in individuals older than the age of 65 years. Clinically, the age of 65 years represents the time point at which the rate of cardiac transplantation begins to decline. Although in younger patients high-risk VAD placement might be attempted to bridge the patient to cardiac transplantation, in older patients transplantation is unlikely and VADs must often be considered destination therapy.

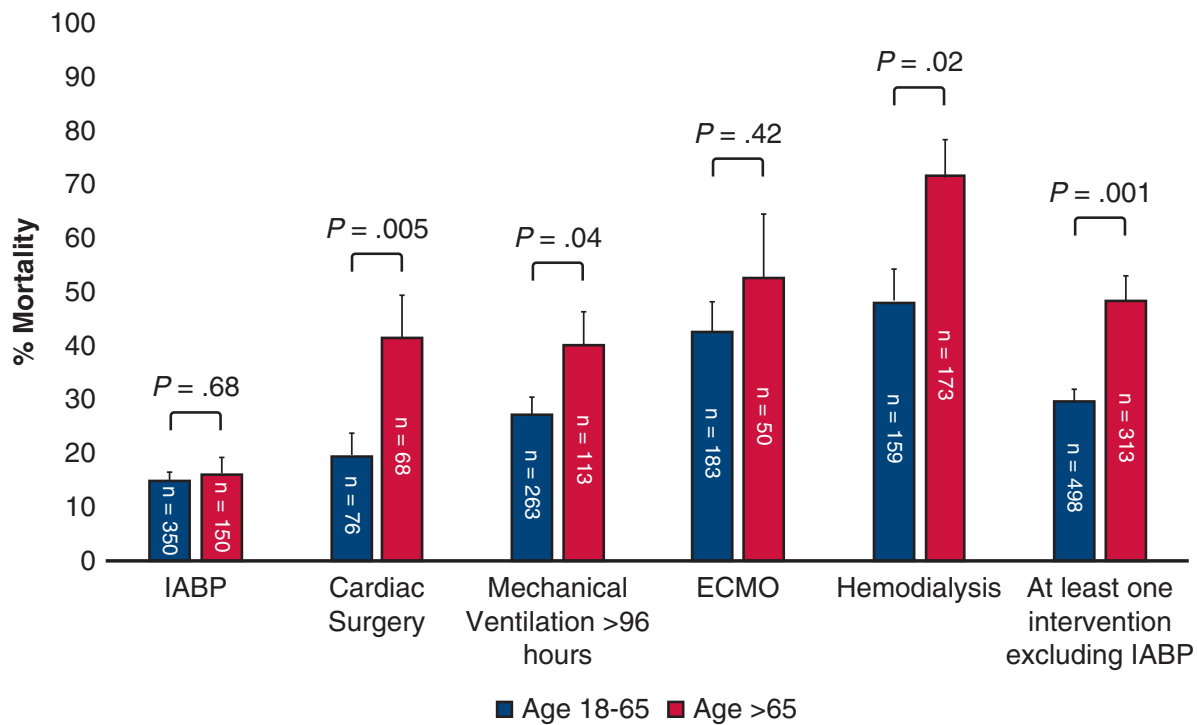

FIGURE 2. In-hospital mortality for patients who received intensive treatments before ventricular assist device placement. Examined treatments included intra-aortic balloon pump $(I A B P)$, cardiac surgery, mechanical ventilation $>96$ hours, extracorporeal membrane oxygenation $(E C M O)$, and hemodialysis. 
TABLE 3. Multivariate analysis of in-hospital mortality after the VAD procedure and sensitivity analysis using age as a continuous variable

\begin{tabular}{|c|c|c|}
\hline & Age dichotomized & Age as a continuous variable \\
\hline Age $>65$ years & $1.77(1.29-2.40)$ & - \\
\hline Female sex & $1.27(0.96-1.67)$ & $1.30(0.99-1.17)$ \\
\hline \multicolumn{3}{|l|}{ Race } \\
\hline White & Reference & Reference \\
\hline Black & $1.02(0.73-1.43)$ & $1.09(0.79-1.52)$ \\
\hline Other* & $1.15(0.80-1.65)$ & $1.17(0.81-1.68)$ \\
\hline Unknown & $1.41(0.90-2.20)$ & $1.42(0.90-2.23)$ \\
\hline \multicolumn{3}{|l|}{ Primary payer } \\
\hline Medicare & Reference & Reference \\
\hline Medicaid & $0.98(0.63-1.53)$ & $1.12(0.72-1.72)$ \\
\hline Private & $0.91(0.67-1.23)$ & $0.99(0.75-1.31)$ \\
\hline Other & $1.22(0.68-2.20)$ & $1.33(0.74-2.38)$ \\
\hline \multicolumn{3}{|l|}{ Hospital region } \\
\hline Midwest & Reference & Reference \\
\hline Northeast & $0.97(0.66-1.43)$ & $0.97(0.65-1.43)$ \\
\hline West & $1.06(0.76-1.49)$ & $1.06(0.75-1.50)$ \\
\hline South & $0.84(0.54-1.32)$ & $0.81(0.65-1.43)$ \\
\hline Household income & $1.12(1.00-1.25)$ & $1.10(0.99-1.23)$ \\
\hline Elective admission & $0.75(0.57-0.98)$ & $0.72(0.55-0.96)$ \\
\hline Year of implantation & $0.95(0.88-1.03)$ & $0.94(0.87-1.02)$ \\
\hline Elixhauser score & $1.01(0.95-1.08)$ & $1.01(0.95-1.09)$ \\
\hline IABP before VAD placement & $0.91(0.69-1.20)$ & $0.92(0.70-1.22)$ \\
\hline High-risk intervention before VAD placement $\ddagger$ & $5.52(4.27-7.13)$ & $5.65(4.35-7.34)$ \\
\hline
\end{tabular}

Because of the nonlinear relationship of age and mortality age and age ${ }^{2}$ were included in the continuous model. The results of mortality as a plot of age against the probability of in-hospital mortality is shown in Figure 1. Data are presented as OR ( $95 \% \mathrm{CI})$. IABP, Intra-aortic balloon pump; VAD, ventricular assist device. *Includes Hispanic, Asian or Pacific Islander, Native American, and other. †Includes self-pay, no charge, and other. †̣ncludes vasopressors, intra-aortic balloon pump, extracorporeal membrane oxygenation, hemodialysis, mechanical ventilation, and same admission cardiac surgery before VAD placement.

Previous studies have shown similar short-term mortality between younger and older VAD recipients. The Interagency Registry for Mechanically Assisted Circulatory Support (INTERMACS) report showed 30-day survival of $93 \%$ for VAD patients aged 70 years or older. ${ }^{8}$ Likewise, a single-center study reported by Adamson and colleagues ${ }^{6}$ showed a 30day survival of $97 \%$ for patients older than 70 years. ${ }^{6}$ In our study $17.2 \%$ of patients aged older than 65 years died in the hospital after VAD implantation. The discrepancy in short-term mortality might in part be explained by differences in measurement. A subset of patients captured in the NIS died $>30$ days after VAD implantation, but while still in-hospital. The high mortality identified in our study could also stem from differences in cohort selection and study periods. INTERMACS collects data from sites approved by the registry, which currently includes 127 centers. In our study, a cohort was extracted on the basis of a weighted sample of hospitals participating in the NIS, which in 2011 included approximately 1000 centers and is the single largest allpayer publicly available database in the United States. The inclusion of hospitals outside of INTERMACS helps explain the higher overall number of VAD placements seen in this study compared with recent reports using the INTERMACS registry. The INTERMACS registry reports a 1-year mortality rate of $20 \%$ in patients after LVAD implantation. Other multi-institutional studies have shown a 1-year mortality of $25 \%$ in patients aged 70 years and older compared with $16 \%$ in patients aged $60-69$ years. ${ }^{10}$ Both are higher than the in-hospital mortality reported in this study, but compare well if our data are projected out.

The number of patients older than age 65 years with heart failure is expected to increase to 3.9 million by the year 2030 . However, the availability of donor hearts remains stable; thus, we expect the utilization of VADs to increase. ${ }^{23,24}$ Although VADs offer a more readily available method of cardiovascular support than heart transplantation, they are associated with significant morbidity, caregiver burden, and complicated end of life care. ${ }^{12,25-27}$ These challenges place further importance on optimizing patient selection and the shared decision-making process before VAD implantation.

The decision to proceed with VAD placement remains a difficult challenge for clinicians. In particular, compared with heart transplantation, the criteria for VAD patient selection are less well defined. ${ }^{28,29}$ Several risk-assessment 

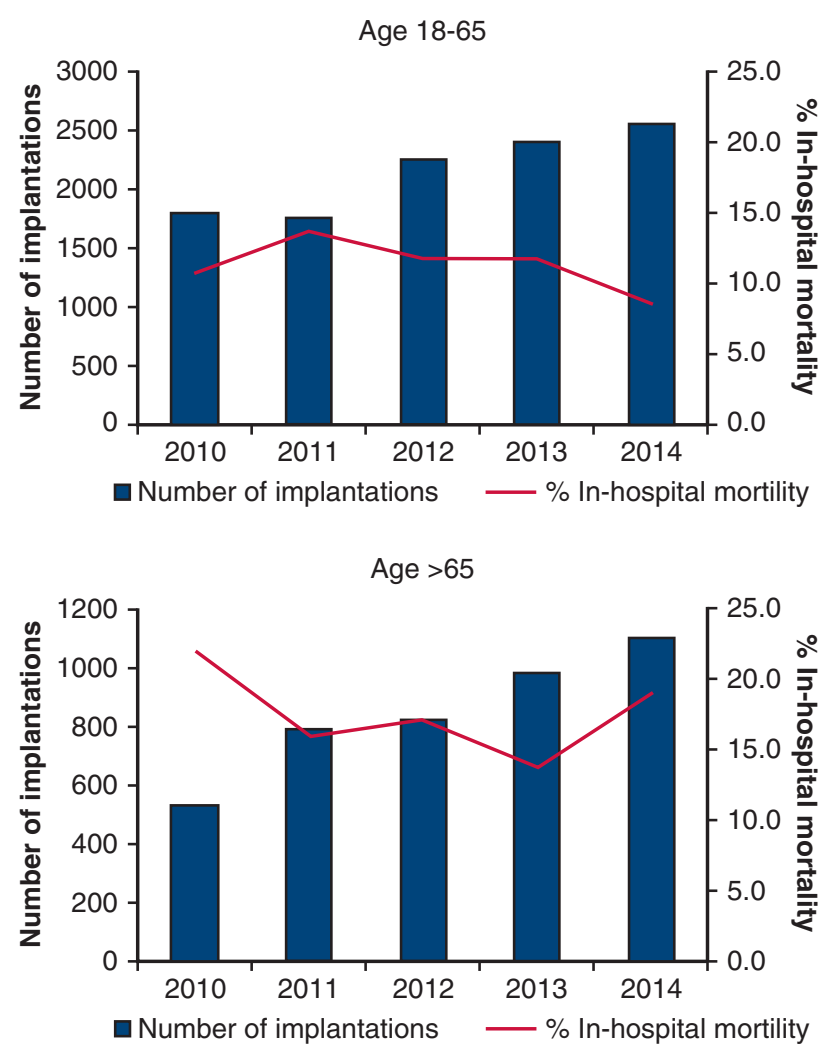

FIGURE 3. Ventricular assist device implantation and in-hospital mortality between 2010 and 2014 for those aged 18-65 years and those older than 65 years.

tools use clinical and laboratory variables to predict postoperative complications, mortality, and functional outcome. ${ }^{30-33}$ Increasingly, measures of frailty are used as a predictor for heightened risk of adverse outcomes. ${ }^{34-36}$ Our study further suggests that the intensity of the immediate medical care should be included in the risk assessment of VAD surgery. Not surprisingly, intensive procedures such as cardiac surgery, ECMO, mechanical ventilation, or hemodialysis before VAD implantation were associated with high in-hospital mortality. This is true for older and younger patients, yet the increase is substantially higher in patients older than the age of 65 years. In our study, we found that nearly $50 \%$ of older patients who had 1 or more intensive procedures before VAD placement died in the hospital. In contrast, IABP had only a minor effect on in-hospital mortality in younger patients and in patients older than 65 years of age it had no significant effect on in-hospital mortality.

Finally, equitable access to this treatment remains a concern. ${ }^{37}$ Older VAD recipients were overwhelmingly white and male. Historical evidence shows decreased access to evidence-based treatment for women and minority patients. ${ }^{38,39}$ Further analysis on access will enable us to address potential disparities and cost considerations as VAD becomes more common.

\section{Limitation}

The findings of this study should be interpreted within the limitations of study design. First, clinical data such as INTERMACS profile, laboratory data, medications, and echocardiography data were not available, limiting our ability to study granular clinical characteristics. The data represent a cross-sectional assessment of device implantation; longitudinal clinical outcomes might offer a more comprehensive understanding of differences in clinical outcomes between patients ages 18-65 years versus patients older than 65 years. For example, we are unable determine readmission rates or long-term complications such as pump thrombosis. In our analysis, we used sample weights that are projected from NIS collected data. This method is

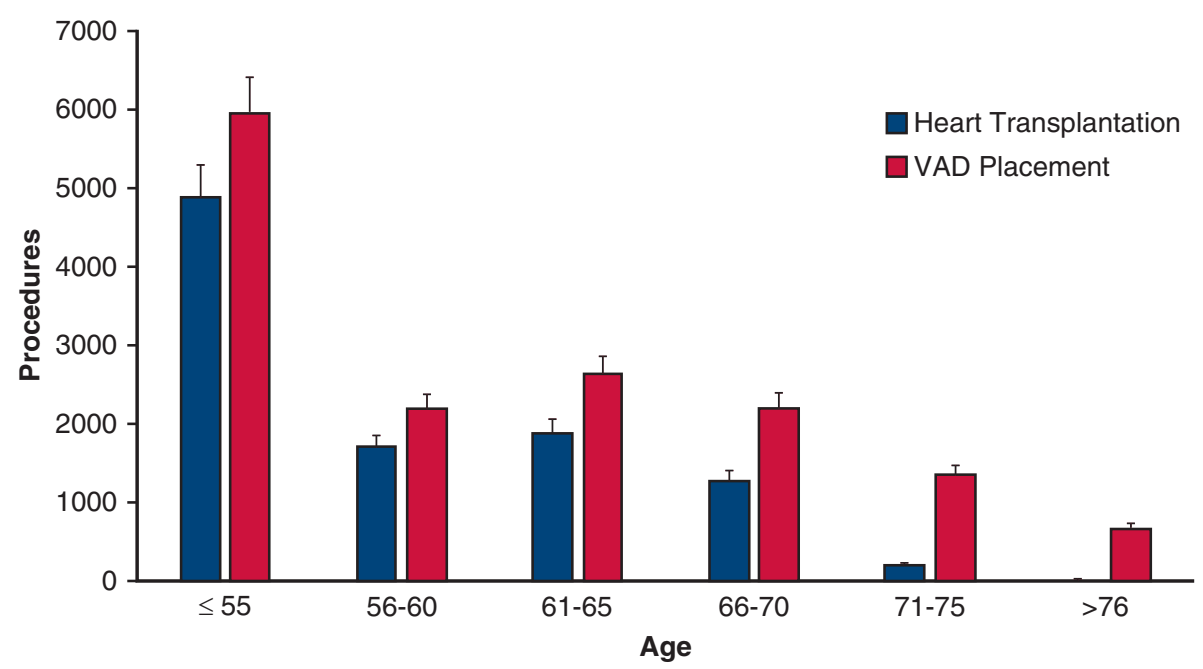

FIGURE 4. Distribution of ventricular assist device $(V A D)$ placement and heart transplantation stratified according to age. After the age of 70 years the opportunity for heart transplantation is exceptionally rare. 


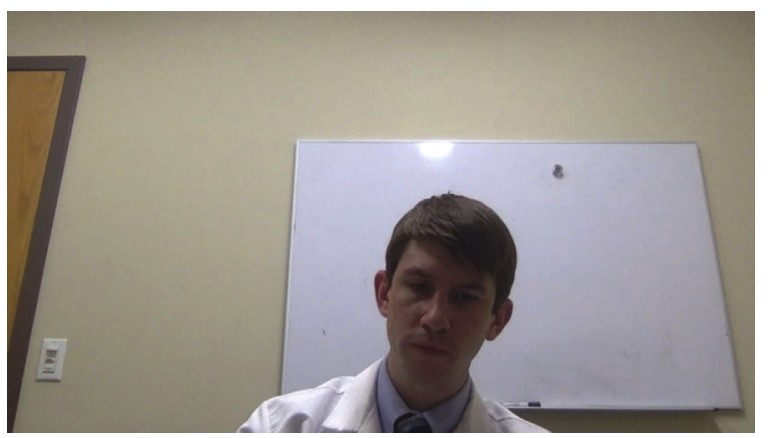

VIDEO 1. The second author (Brooks Udelsman, MD) presenting a short summary of the study, highlighting the central findings and conclusions. Video available at: https://www.jtcvs.org/article/S0022-5223(18)329623/fulltext.

designed to help study relatively rare events, such as VAD placement, and to identify national trends. This method has been validated several times, including in the study of VAD and congestive heart disease. . $^{13,17,18}$

Although most VADs are left-sided, it is not possible to identify the number of right VADs implanted in this study. On the basis of INTERMACS data from this time period there were only 116 right-sided VADs placed between 2006 and $2014 .{ }^{8}$ Although it is unlikely that all of these right VADs were implanted during our study period of 2010-2014, if they were they would only represent $0.8 \%$ of the study population. It is also not possible to identify the type or model of VAD device implanted. Furthermore, NIS data do not distinguish between VADs that were used for destination therapy versus bridge to transplantation because there are no administrative codes for that distinction.

We analyzed the frequency of heart transplantations in the NIS database and determined that only 229 patients older than 70 years received a heart transplantation between 2010 and 2014; thus, most VADs for patients older than 70 years were for destination therapy. We chose to investigate outcomes of patients between the years of 2010 and 2014 , because this represents a period of relatively stability in administrative coding and allowed for more robust analysis. However, the field advances rapidly. Although data in this study are recent, it is possible they do not perfectly reflect contemporary trends. Finally, we are limited in ascertainment of true cost of hospital care accrued during the index admission; our study only used hospital charges as a proxy measure.

\section{CONCLUSIONS}

In this nationally representative cohort, older patients who underwent major procedures during the hospitalization before VAD implantation had high in-hospital mortality $(48.2 \%)$ and a low likelihood of cardiac transplantation. Future efforts to improve patient selection might help better align destination VAD implantation with those most likely to benefit.

\section{Conflict of Interest Statement}

Authors have nothing to disclose with regard to commercial support.

The authors thank Dr Steven Worthington for help with statistical analyses. The authors also thank the Institute for Quantitative Social Science at Harvard University for providing access to cluster computing.

\section{References}

1. Benjamin EJ, Virani SS, Callaway CW, Chang AR, Cheng S, Chiuve SE, et al. Heart disease and stroke statistics-2018 update: a report from the American Heart Association [erratum in 2018;137:e493]. Circulation. 2018;137:e67-492.

2. Butler CR, Jugdutt BI. Mechanical circulatory support for elderly heart failure patients. Heart Fail Rev. 2012;17:663-9.

3. Benjamin EJ, Blaha MJ, Chiuve SE, Cushman M, Das SR, Deo R, et al. Heart disease and stroke statistics-2017 update: a report from the American Heart Association. Circulation. 2017;135:e146-603.

4. Cooper LB, Lu D, Mentz RJ, Rogers JG, Milano CA, Felker GM, et al. Cardiac transplantation for older patients: characteristics and outcomes in the septuagenarian population. J Heart Lung Transplant. 2016;35:362-9.

5. Lund LH, Edwards LB, Kucheryavaya AY, Dipchand AI, Benden C, Christie JD, et al. The registry of the International Society for Heart and Lung Transplantation: thirtieth official adult heart transplant report-2013; focus theme: age. $J$ Heart Lung Transplant. 2013;32:951-64.

6. Adamson RM, Stahovich M, Chillcott S, Baradarian S, Chammas J, Jaski B, et al. Clinical strategies and outcomes in advanced heart failure patients older than 70 years of age receiving the HeartMate II left ventricular assist device. J Am Coll Cardiol. 2011;57:2487-95.

7. Atluri P, Goldstone AB, Kobrin DM, Cohen JE, MacArthur JW, Howard JL, et al. Ventricular assist device implant in the elderly is associated with increased, but respectable risk: a multi-institutional study. Ann Thorac Surg. 2013;96:141-7.

8. Kirklin JK, Naftel DC, Pagani FD, Kormos RL, Stevenson LW, Blume ED, et al. Seventh INTERMACS annual report: 15,000 patients and counting. J Heart Lung Transplant. 2015;34:1495-504

9. Pagani FD, Miller LW, Russell SD, Aaronson KD, John R, Boyle AJ, et al. Extended mechanical circulatory support with a continuous-flow rotary left ventricular assist device. J Am Coll Cardiol. 2009;54:312-21.

10. Kim JH, Singh R, Pagani FD, Desai SS, Haglund NA, Dunlay SM, et al. Ventricular assist device therapy in older patients with heart failure: characteristics and outcomes. J Card Fail. 2016;22:981-7.

11. McIlvennan CK, Allen LA, Nowels C, Brieke A, Cleveland JC, Matlock DD. Decision making for destination therapy left ventricular assist devices: "There was no choice" versus "I thought about it an awful lot" Circ Cardiovasc Qual Outcomes. 2014; 7:374-80.

12. Ottenberg AL, Cook KE, Topazian RJ, Mueller LA, Mueller PS, Swetz KM. Choices for patients "without a choice": interviews with patients who received a left ventricular assist device as destination therapy. Circ Cardiovasc Qual Outcomes. 2014;7:368-73.

13. Shah N, Agarwal V, Patel N, Deshmukh A, Chothani A, Garg J, et al. National trends in utilization, mortality, complications, and cost of care after left ventricular assist device implantation from 2005 to 2011. Ann Thorac Surg. 2016;101:1477-84.

14. Shah N, Chothani A, Agarwal V, Deshmukh A, Patel N, Garg J, et al. Impact of annual hospital volume on outcomes after left ventricular assist device (LVAD) implantation in the contemporary era. J Card Fail. 2016;22:232-7.

15. Sheetz KH, Krell RW, Englesbe MJ, Birkmeyer JD, Campbell DA Jr, Ghaferi AA. The importance of the first complication: understanding failure to rescue after emergent surgery in the elderly. J Am Coll Surg. 2014;219:365-70.

16. HCUP. NIS overview. Available at: www.hcup-us.ahrq.gov/nisoverview.jsp. Accessed October 20, 2016.

17. Kumar G, Kumar N, Taneja A, Kaleekal T, Tarima S, McGinley E, et al. Nationwide trends of severe sepsis in the 21st century (2000-2007). Chest. 2011;140: 1223-31.

18. Deshmukh A, Kumar G, Kumar N, Nanchal R, Gobal F, Sakhuja A, et al. Effect of joint national committee VII report on hospitalizations for hypertensive emergencies in the United States. Am J Cardiol. 2011;108:1277-82.

19. Lampropulos JF, Kim N, Wang Y, Desai MM, Barreto-Filho JA, Dodson JA, et al. Trends in left ventricular assist device use and outcomes among Medicare beneficiaries, 2004-2011. Open Heart. 2014;1:e000109. 
20. Elixhauser A, Steiner C, Harris DR, Coffey RM. Comorbidity measures for use with administrative data. Med Care. 1998;36:8-27.

21. HCUP. Elixhauser Comorbidity Software, Version 3.7. Available at: www.hcup-us. ahrq.gov/toolssoftware/comorbidity/comorbidity.jsp. Accessed October 20, 2016.

22. Chen H, Cohen P, Chen S. Biased odds ratios from dichotomization of age. Stat Med. 2007;26:3487-97.

23. Heidenreich PA, Albert NM, Allen LA, Bluemke DA, Butler J, Fonarow GC, et al. Forecasting the impact of heart failure in the United States: a policy statement from the American Heart Association. Circ Heart Fail. 2013;6:606-19.

24. Miller LW, Guglin M, Rogers J. Cost of ventricular assist devices: can we afford the progress? Circulation. 2013;127:743-8.

25. Dunlay SM, Strand JJ, Wordingham SE, Stulak JM, Luckhardt AJ, Swetz KM. Dying with a left ventricular assist device as destination therapy. Circ Heart Fail. 2016;9:e003096.

26. Mcllvennan CK, Jones J, Allen LA, Swetz KM, Nowels C, Matlock DD. Bereaved caregiver perspectives on the end-of-life experience of patients with a left ventricular assist device. JAMA Intern Med. 2016;176:534-9.

27. Swetz KM, Ottenberg AL, Freeman MR, Mueller PS. Palliative care and end-oflife issues in patients treated with left ventricular assist devices as destination therapy. Curr Heart Fail Rep. 2011;8:212-8.

28. Feldman D, Pamboukian SV, Teuteberg JJ, Birks E, Lietz K, Moore SA, et al. The 2013 International Society for Heart and Lung Transplantation guidelines for mechanical circulatory support: executive summary. J Heart Lung Transplant. 2013;32:157-87.

29. Mehra MR, Canter CE, Hannan MM, Semigran MJ, Uber PA, Baran DA, et al. The 2016 International Society for Heart Lung Transplantation listing criteria for heart transplantation: a 10-year update. J Heart Lung Transplant. 2016;35:1-23.
30. Miller LW, Guglin M. Patient selection for ventricular assist devices: a moving target. J Am Coll Cardiol. 2013;61:1209-21.

31. Cowger J, Sundareswaran K, Rogers JG, Park SJ, Pagani FD, Bhat G, et al. 70 the HeartMate II risk score: predicting survival in candidates for left ventricular assist device support. J Heart Lung Transplant. 2011;30:S31.

32. Porepa LF, Starling RC. Destination therapy with left ventricular assist devices: for whom and when? Can J Cardiol. 2014;30:296-303.

33. Lietz K, Long JW, Kfoury AG, Slaughter MS, Silver MA, Milano CA, et al. Outcomes of left ventricular assist device implantation as destination therapy in the post-REMATCH era: implications for patient selection. Circulation. 2007;116: 497-505.

34. Flint KM, Matlock DD, Lindenfeld J, Allen LA. Frailty and the selection of patients for destination therapy left ventricular assist device. Circ Heart Fail. 2012; 5:286-93.

35. Hiesinger W, Boyd JH, Woo YJ. Ventricular assist device implantation in the elderly. Ann Cardiothorac Surg. 2014;3:570-2.

36. Shah R, Attwood K, Arya S, Hall DE, Johanning JM, Gabriel E, et al. Association of frailty with failure to rescue after low-risk and high-risk inpatient surgery. JAMA Surg. 2018;153:e180214.

37. Joyce DL, Conte JV, Russell SD, Joyce LD, Chang DC. Disparities in access to left ventricular assist device therapy. J Surg Res. 2009;152:111-7.

38. Dunlay SM, Roger VR. Gender differences in the pathophysiology, clinical presentation, and outcomes of ischemic heart failure. Curr Heart Fail Rep. 2012;9: 267-76.

39. Davis AM, Vinci LM, Okwuosa TM, Chase AR, Huang ES. Cardiovascular health disparities: a systematic review of health care interventions. Med Care Res Rev. 2007;64:29S-100S.

Readers who found these articles interesting may also like to read the following papers found in recent and future issues of our sister publications, Seminars in Thoracic and Cardiovascular Surgery and Operative Techniques in Thoracic and Cardiovascular Surgery!

\section{Adult: Mechanical Circulatory Support}

STATE OF THE ART: Interhospital ECMO Transport: Regional Focus. Yaron D. Barac. Semin Thoracic Surg 2019: In press

ORIGINAL SUBMISSION: Surgical Technique for Redo-Sternotomy Sparing Heartware HVAD Exchanges. Thomas Haberl. Oper Tech Thorac Cardiovasc Surg: In press

ORIGINAL SUBMISSION: Novel Cannulation Technique for Temporary Right Ventricular Assist Device After LVAD placement. Leora T. Yarboro. Oper Tech Thorac Cardiovasc Surg: In press

ORIGINAL SUBMISSION: Better With Time: An Economic Assessment of Long-Term Mechanical Circulatory Support in a Population Surviving at Least 1 Year with a Left Ventricular Assist Device. Pavan Atluri. Semin Thoracic Surg 2018: In press

ORIGINAL SUBMISSION: Implantation of the HeartMate 3 -Description of the Surgical Technique. Friedhelm Beyersdorf. Oper Tech Thorac Cardiovasc 2017: 173-185

ORIGINAL SUBMISSION: Greater Omentum Wrapping to Treat Systemic Vad Infections. Sebastian Schulte - Eistrup. Oper Tech Thorac Cardiovasc 2017: 186-197 
TABLE E1. In-hospital intensive procedures and treatments

\begin{tabular}{|c|c|}
\hline Description & ICD-9 code \\
\hline Intra-aortic balloon pump & 37.61 \\
\hline Mechanical ventilation & $96.70,96.71,96.72$ \\
\hline Hemodialysis & 39.95 \\
\hline ECMO & 37.62 \\
\hline Invasive mechanical ventilation $\geq 96$ hours & 96.72 \\
\hline \multicolumn{2}{|l|}{ Cardiac surgery } \\
\hline \multicolumn{2}{|l|}{ Operations on valves and septa of heart } \\
\hline Closed heart valvotomy, unspecified valve & 35 \\
\hline Closed heart valvotomy, aortic valve & 35.01 \\
\hline Closed heart valvotomy, mitral valve & 35.02 \\
\hline Closed heart valvotomy, pulmonary valve & 35.03 \\
\hline Closed heart valvotomy, tricuspid valve & 35.04 \\
\hline Endovascular replacement of aortic valve & 35.05 \\
\hline Transapical replacement of aortic valve & 35.06 \\
\hline Endovascular replacement of pulmonary valve & 35.07 \\
\hline Transapical replacement of pulmonary valve & 35.08 \\
\hline Endovascular replacement of unspecified heart valve & 35.09 \\
\hline Open heart valvuloplasty without replacement, unspecified valve & 35.1 \\
\hline Open heart valvuloplasty of aortic valve without replacement & 35.11 \\
\hline Open heart valvuloplasty of mitral valve without replacement & 35.12 \\
\hline Open heart valvuloplasty of pulmonary valve without replacement & 35.13 \\
\hline Open heart valvuloplasty of tricuspid valve without replacement & 35.14 \\
\hline Open and other replacement of unspecified heart valve & 35.2 \\
\hline Open and other replacement of aortic valve with tissue graft & 35.21 \\
\hline Open and other replacement of aortic valve & 35.22 \\
\hline Open and other replacement of mitral valve with tissue graft & 35.23 \\
\hline Open and other replacement of mitral valve & 35.24 \\
\hline Open and other replacement of pulmonary valve with tissue graft & 35.25 \\
\hline Open and other replacement of pulmonary valve & 35.26 \\
\hline Open and other replacement of tricuspid valve with tissue graft & 35.27 \\
\hline Open and other replacement of tricuspid valve & 35.28 \\
\hline Operations on papillary muscle & 35.31 \\
\hline Operations on chordae tendineae & 35.32 \\
\hline Annuloplasty & 35.33 \\
\hline Infundibulectomy & 35.34 \\
\hline Operations on trabeculae carneae cordis & 35.35 \\
\hline Operations on other structures adjacent to valves of heart & 35.39 \\
\hline Enlargement of existing atrial septal defect & 35.41 \\
\hline Creation of septal defect in heart & 35.42 \\
\hline Repair of unspecified septal defect of heart with prosthesis & 35.5 \\
\hline Repair of atrial septal defect with prosthesis, open technique & 35.51 \\
\hline Repair of atrial septal defect with prosthesis, closed technique & 35.52 \\
\hline Repair of ventricular septal defect with prosthesis, open technique & 35.53 \\
\hline Repair of endocardial cushion defect with prosthesis & 35.54 \\
\hline Repair of ventricular septal defect with prosthesis, closed technique & 35.55 \\
\hline Repair of unspecified septal defect of heart with tissue graft & 35.6 \\
\hline Repair of atrial septal defect with tissue graft & 35.61 \\
\hline Repair of ventricular septal defect with tissue graft & 35.62 \\
\hline Repair of endocardial cushion defect with tissue graft & 35.63 \\
\hline Other and unspecified repair of unspecified septal defect of heart & 35.7 \\
\hline Other and unspecified repair of atrial septal defect & 35.71 \\
\hline Other and unspecified repair of ventricular septal defect & 35.72 \\
\hline Other and unspecified repair of endocardial cushion defect & 35.73 \\
\hline
\end{tabular}




\section{Description}

ICD-9 code

Total repair of tetralogy of Fallot

Total repair of total anomalous pulmonary venous connection

Total repair of truncus arteriosus

Total correction of transposition of great vessels, not elsewhere classified

Interatrial transposition of venous return

Creation of conduit between right ventricle and pulmonary artery

Creation of conduit between left ventricle and aorta

Creation of conduit between atrium and pulmonary artery

Revision of corrective procedure on heart

Percutaneous balloon valvuloplasty

Percutaneous mitral valve repair with implant

Other operations on septa of heart

Other operations on valves of heart

Operations on vessels of heart

Open chest coronary artery angioplasty

Intracoronary artery thrombolytic infusion

Insertion of non-drug-eluting coronary artery stent(s)

Insertion of drug-eluting coronary artery stent(s)

Other removal of coronary artery obstruction

Aortocoronary bypass for heart revascularization, not otherwise specified

(Aorto)coronary bypass of 1 coronary artery

(Aorto)coronary bypass of 2 coronary arteries

(Aorto)coronary bypass of 3 coronary arteries

(Aorto)coronary bypass of 4 or more coronary arteries

Single internal mammary-coronary artery bypass

Double internal mammary-coronary artery bypass

Abdominal-coronary artery bypass

Other bypass anastomosis for heart revascularization

Heart revascularization by arterial implant

Open chest transmyocardial revascularization

Other transmyocardial revascularization

Endoscopic transmyocardial revascularization

Percutaneous transmyocardial revascularization

Other heart revascularization

Repair of aneurysm of coronary vessel

Other operations on vessels of heart

Cardiotomy and pericardiotomy

Incision of heart, not otherwise specified

Cardiotomy

Pericardiotomy

Pericardiectomy and excision of lesion of heart

Pericardiectomy

Excision of aneurysm of heart

Excision or destruction of other lesion or tissue of heart, open approach

Excision or destruction of other lesion or tissue of heart, endovascular approach

Excision, destruction, or exclusion of left atrial appendage

Excision or destruction of other lesion or tissue of heart, thoracoscopic approach

Major aortic dissection or aneurysm repair

Unspecified site

Ascending aorta 
TABLE E1. Continued

\section{Description}

ICD-9 code

Thoracoabdominal aneurysm, without mention of rupture

Aortic aneurysm of unspecified site without mention of rupture

ICD-9, International Classification of Diseases, Ninth Revision; ECMO, extracorporeal membrane oxygenation.

TABLE E2. Individual components of Elixhauser comorbidity index

\begin{tabular}{|c|c|c|c|c|c|c|c|}
\hline & \multicolumn{2}{|c|}{$\begin{array}{c}\text { Overall } \\
(\mathrm{n}=\mathbf{1 5 , 0 2 1} \pm \mathbf{1 0 5 5})\end{array}$} & \multicolumn{2}{|c|}{$\begin{array}{l}\text { Ages } 18-65 \text { years } \\
(n=10,790 \pm 782)\end{array}$} & \multicolumn{2}{|c|}{$\begin{array}{l}\text { Age older than } 65 \text { years } \\
\quad(n=4231 \pm 329)\end{array}$} & \multirow[b]{2}{*}{$P$ value } \\
\hline & n $(\%)$ & $\mathbf{S E}$ & $\mathbf{n}$ & SE & $\mathbf{n}$ & SE & \\
\hline Congestive heart failure* & $85(0.6)$ & 39 & $71(0.7)$ & 35 & $14(0.3)$ & 8 & .24 \\
\hline Valvular disease* & $30(0.2)$ & 16 & $25(0.2)$ & 15 & $5(0.1)$ & 5 & .54 \\
\hline Pulmonary circulation disorders & $44(0.3)$ & 21 & $39(0.4)$ & 21 & $5(0.1)$ & 5 & .29 \\
\hline Peripheral vascular disorders & $1325(8.8)$ & 121 & $793(7.4)$ & 90 & $532(12.6)$ & 61 & $<.001$ \\
\hline Hypertension & $6628(44.1)$ & 518 & $4568(42.3)$ & 375 & $2060(48.7)$ & 179 & .03 \\
\hline Paralysis & $359(2.4)$ & 47 & $264(2.5)$ & 40 & $94(2.2)$ & 21 & .71 \\
\hline Other neurologic disorders & $783(5.2)$ & 90 & $521(4.8)$ & 69 & $261(6.2)$ & 39 & .12 \\
\hline Chronic pulmonary disease & $2715(18.1)$ & 241 & $1817(16.8)$ & 178 & $898(21.2)$ & 98 & .02 \\
\hline Diabetes, uncomplicated & $3928(26.1)$ & 301 & $2739(25.4)$ & 225 & $1188(28.1)$ & 111 & .15 \\
\hline Diabetes, complicated & $1085(7.2)$ & 102 & $722(6.7)$ & 79 & $363(8.6)$ & 47 & .08 \\
\hline Hypothyroidism & $1744(11.6)$ & 145 & $1108(10.2)$ & 106 & $636(15.0)$ & 68 & $<.001$ \\
\hline Chronic kidney disease & $5989(39.9)$ & 481 & $3905(36.1)$ & 330 & $2084(49.2)$ & 189 & $<.001$ \\
\hline Liver disease & $533(3.5)$ & 62 & $406(3.8)$ & 52 & $127(3.0)$ & 27 & .31 \\
\hline Peptic ulcer disease, excluding bleeding & $5(0.03)$ & 5 & $5(0.04)$ & 5 & $0(0)$ & 0 & 1 \\
\hline Acquired immune deficiency syndrome & $20(0.13)$ & 10 & $20(0.19)$ & 10 & $0(0)$ & 0 & 1 \\
\hline Lymphoma & $167(1.1)$ & 34 & $109(1.0)$ & 26 & $58(1.4)$ & 20 & .4 \\
\hline Metastatic cancer & $35(0.2)$ & 13 & $20(0.18)$ & 10 & $15(0.4)$ & 9 & .37 \\
\hline Solid tumor without metastasis & $140(0.9)$ & 31 & $85(0.8)$ & 22 & $55(1.3)$ & 19 & .22 \\
\hline Rheumatoid arthritis/collagen vascular diseases & $178(1.2)$ & 32 & $114(1.1)$ & 25 & $64(1.5)$ & 18 & .29 \\
\hline Coagulopathy & $5778(38.5)$ & 482 & $4010(37.2)$ & 360 & $1768(41.8)$ & 152 & .02 \\
\hline Obesity & $2431(16.2)$ & 187 & $2058(19.1)$ & 167 & $373(8.8)$ & 51 & $<.001$ \\
\hline Weight loss & $4102(27.3)$ & 346 & $2721(25.2)$ & 250 & $1381(32.6)$ & 130 & .002 \\
\hline Fluid and electrolyte disorders & $9778(65.1)$ & 759 & $7192(66.7)$ & 577 & $2586(61.1)$ & 215 & .007 \\
\hline Blood loss anemia & $255(1.7)$ & 44 & $172(1.6)$ & 35 & $83(2.0)$ & 22 & .49 \\
\hline Deficiency anemias & $3169(21.3)$ & 315 & $2310(21.4)$ & 242 & $886(20.9)$ & 96 & .76 \\
\hline Alcohol use & $385(2.6)$ & 50 & $336(3.1)$ & 45 & $49(1.1)$ & 17 & .003 \\
\hline Drug abuse & $330(2.2)$ & 49 & $321(3.0)$ & 48 & $9(0.2)$ & 7 & $<.001$ \\
\hline Psychoses & $483(3.2)$ & 66 & 389 (3.6) & 61 & $94(2.2)$ & 23 & .08 \\
\hline Depression & $1639(10.9)$ & 153 & $1233(11.4)$ & 119 & $406(9.6)$ & 57 & .14 \\
\hline
\end{tabular}

$S E$, Standard error of the mean. *Note that the diagnosis of congestive heart failure and valvular heart disease are primary diagnoses for a large percentage of patients in this study and thus not readily captured by our Elixhauser comorbidity index. Because of the ubiquity of these diagnoses in the study population they are essentially dropped in this analysis. 
TABLE E3. Univariate analysis for in-hospital mortality after the VAD procedure

\begin{tabular}{|c|c|c|}
\hline & OR $(95 \%$ CI $)$ & $P$ value \\
\hline Age older than 65 years & $1.02(1.01-1.04)$ & $<.001$ \\
\hline Female sex & $1.22(0.94-1.59)$ & .14 \\
\hline \multicolumn{3}{|l|}{ Race } \\
\hline White & Reference & - \\
\hline Black & $0.77(0.58-1.03)$ & .08 \\
\hline Other* & $1.19(0.86-1.64)$ & .29 \\
\hline Unknown & $1.40(0.96-2.06)$ & .08 \\
\hline \multicolumn{3}{|l|}{ Primary payer } \\
\hline Medicare & Reference & - \\
\hline Medicaid & $0.89(0.63-1.72)$ & .52 \\
\hline Private & $0.99(0.75-1.31)$ & .34 \\
\hline Other $\dagger$ & $1.33(0.74-2.38)$ & .47 \\
\hline \multicolumn{3}{|l|}{ Hospital region } \\
\hline Midwest & Reference & \\
\hline Northeast & $1.00(0.72-1.40)$ & .99 \\
\hline West & $0.88(0.64-1.21)$ & .41 \\
\hline South & $0.82(0.53-1.26)$ & .37 \\
\hline Household income & $1.16(1.05-1.27)$ & .003 \\
\hline Elective admission & $0.65(0.50-0.85)$ & .002 \\
\hline Year of implantation & $0.96(0.88-1.05)$ & .35 \\
\hline Elixhauser score & $1.02(0.95-1.07)$ & .72 \\
\hline IABP before VAD placement & $1.29(1.00-1.66)$ & .05 \\
\hline High-risk intervention before VAD placement & $5.50(4.38-6.91)$ & $<.001$ \\
\hline
\end{tabular}

Age $\times$ Age was used in addition to Age as a continuous variable because of the nonlinear relationship of age and mortality. $O R$, Odds ratio; $C I$, confidence interval; IABP, intraaortic balloon pump; VAD, ventricular assist device. *Includes Hispanic, Asian or Pacific Islander, Native American, and other. †Includes self-pay, no charge, and other. $\ddagger$ Includes vasopressors, IABP, extracorporeal membrane oxygenation, hemodialysis, mechanical ventilation, and same admission cardiac surgery before VAD placement. 